Çukurova Üniversitesi Mühendislik Mimarlık Fakültesi Dergisi, 31(ÖS 1), ss. ÖS 147-ÖS 153, Ağustos 2016

Cukurova University Journal of the Faculty of Engineering and Architecture, 31(ÖS 1), pp. SI 147-SI 153, August 2016

\title{
Düşük Alaşımlı Çelik Kaynaklarda Sıcak Çatlak Oluşumunun Matematiksel Olarak Modellenmesi
}

\author{
Alptekin DURMUŞOĞLU" \\ ${ }^{1}$ Gaziantep Üniversitesi, Mühendislik Fakültesi, Endüstri Mühendisliği Bölümü, Gaziantep
}

Geliş tarihi: 12.01.2016 Kabul tarihi:04.04.2016

\section{Özet}

Çelik alaşımların kaynak malzemesi olarak yaygın kullanımı; alaşım özelliklerinin ve kaynak koşullarının, sıcak çatlamaların oluşumundaki etkilerinin araştırılmasında önemli bir rol oynamıştır. Deneysel çalışmalar, metallerin kimyasal özelliklerinin, alaşımlı kaynakların sıcak çatlamayla sonuçlanmasında etkin rol oynadığını gösterse de, faktörlerin etkilerinin büyüklüklerine göre ayrıştırılması tam anlamıyla gerçekleştirilememiştir. Bu çalışmada; Cambridge Üniversitesi tarafından; "Malzeme Veri Kütüphanesi”nde yayınlanan deney sonuçları analiz edilerek; sıcak çatlamayı belirleyen faktörlerin matematiksel olarak modellenmesi hedeflenmiştir. Bu amaçla kurulan modeller arasında \%81.8 tahmin doğruluğuyla "En İyi İlk Karar Ağacı" (BFTree) en iyi çözüm üreten yöntem olmuş, bilimsel yazında aynı veri setini kullanan çalışmalara göre daha yüksek doğruluk oranını yakalamıştır.

Anahtar Kelimeler: Sıcak çatlama, Düşük alaşımlı çelik kaynaklar, Matematiksel model

\section{Mathematical Modelling of the Hot Crack Formation in Low Steel Alloy Welds}

\begin{abstract}
The wide usage of steel alloys as the welding material has played an important role through the research on the role of alloy features and welding conditions on the formation of hot cracks. Although the experimental studies indicate that, chemical structure of metals have major role on the hot crack formation, effects of the factors have not been decomposed completely yet. In this paper, it is aimed to develop a mathematical model explaining the factors causing hot cracks by utilizing the results of the experiments published by the Cambridge University in the Material Data Library. "Best First Tree" has been the model producing the best results with the forecasting accuracy of \%81.8 among the model alternatives and it reached a higher accuracy when compared with the studies using the same data.
\end{abstract}

Keywords: Hot cracking, Low alloy steel welds, Mathematical model

\footnotetext{
* Sorumlu yazar (Corresponding author): Alptekin DURMUŞOĞLU, Mühendislik Fakültesi, Endüstri Mühendisliği Bölümü, Gaziantep. durmusoglu@gantep.edu.tr
} 


\section{GíRiş}

Alaşımların kaynak malzemesi olarak kullanılmasında rastlanılan en önemli problemler; deformasyon, sıcak çatlama, pürüzlülük ve azalan dayanım olarak sıralanmaktadır [1]. Kaynağın genel fonksiyonun, güvenilirliğinin ve dayanımının etkilenmesi dolayısıyla, sıcak çatlamalar bu problemler arasında en önemli olanıdır. Sıcak çatlaklar, solidüs (katılaşma) sıcaklığı bölgesinde veya dar katılaşma aralığında oluşurlar. Nedeni, tane segregasyonu yani katı taneler arasında düşük sıcaklıkta eriyen maddelerin toplanması ve bunların çekme gerilmelerine dayanamayıp ayrılmasıdır [2]. Kaynaklarda sıcak çatlak kavramı doğru kaynak koşullarının oluşturulmasında halen başlica meselelerden biridir [3]. Alaşımların sıcak çatlamayla sonuçlanmasındaki en önemli faktör, alaşım içerisindeki metallerin kimyasal özellikleridir [4]. Ancak diğer kaynak parametrelerinin de etkisinin olması, etkilerin faktörlere göre ayrıştırılmasını zorlaştırmaktadır. Bilimsel yazında sıcak çatlamanın önlenmesine yönelik olarak malzeme seçimiyle ilgili oldukça fazla sayıda çalışma olmasına karşın; ortaya konulan sonuçlar genelde fiziksel ve doğrusal modellerle sınırlı kalmış, faktörler arasındaki kompleks ilişkiler tam anlamıyla gösterilememiştir.

Bu çalışmada; Cambridge Üniversitesi'nin Malzeme Algoritmaları Projesi kapsamında gerçekleştirilen deney sonuçlarının yayınladığı; "Malzeme Veri Kütüphanesi”ndeki veri setleri [5] kullanılarak; sıcak çatlamayı belirleyen faktörlerin matematiksel olarak modellenmesi amaçlanmıştır. $\mathrm{Bu}$ kapsamda kullanılan veri setinde yer alan değişkenler Çizelge 1'de özetlenmiştir. Söz konusu değişkenlerden sekizi; oluşturulan alaşımlardaki karbon, silikon, manganez, fosfor, nikel, krom ve molibdenin ağırlıkça yüzdeleri ifade etmektedir. Mikro-alaşım malzemeleri bahsi geçen deneylerde kullanılmamış olduğundan bu çalışmada da kapsam dışında tutulmuştur. Geri kalan beş faktör ise; kaynak koşullarını gösteren; kaynak akım şiddeti, kaynak çalışma gerilimi, kaynak hareket hızı, kaynak açısı, ön 1sıtma derecesi gibi değişkenlerdir. Belirtilen değişkenlerin dışında sıcak çatlamanın oluşup oluşmadığını gösteren "ikili” (binary) bir değişken de deney sonucunu işaret edecek şekilde yapılandırılmıştır. Sıfır (0) değeri çatlağın oluşmadığını; bir (1) ise çatlak oluştuğu göstermektedir. Mevcut veri setinde sıcak çatlağın oluşmadığı 95; oluştuğu 59 deney sonucu yer almaktadir.

Çizelge 1. Sıcak çatlamada etkili olduğu düşünülen parametreler

\begin{tabular}{|l|c|c|}
\hline Parametre Adı & Simge & Birim \\
\hline Karbon (A1) & $\mathrm{C}$ & \% Ağırlık \\
\hline Silikon (A2) & $\mathrm{Si}$ & \% Ağırlık \\
\hline Manganez (A3) & $\mathrm{Mn}$ & \% Ağırlık \\
\hline Fosfor (A4) & $\mathrm{P}$ & \% Ağırlık \\
\hline Sülfür (A5) & $\mathrm{S}$ & \% Ağırlık \\
\hline Nikel (A6) & $\mathrm{Ni}$ & \% Ağırlık \\
\hline Krom (A7) & $\mathrm{Cr}$ & $\%$ Ağırlık \\
\hline Molibden (A8) & $\mathrm{Mo}$ & $\%$ Ağırlık \\
\hline $\begin{array}{l}\text { Kaynak akım şiddeti } \\
\text { (A9) }\end{array}$ & $\mathrm{A}$ & Amper \\
\hline $\begin{array}{l}\text { Kaynak çalışma } \\
\text { gerilimi (A10) }\end{array}$ & $\mathrm{V}$ & Volt \\
\hline $\begin{array}{l}\text { Kaynak hareket hızı } \\
\text { (A11) }\end{array}$ & $\mathrm{S}_{\mathrm{T}}$ & cm/dk \\
\hline Kaynak açısı (A12) & $\mathrm{A}_{\mathrm{G}}$ & derece \\
\hline $\begin{array}{l}\text { Ön 1sıtma derecesi } \\
\text { (A13) }\end{array}$ & $\mathrm{P}_{\mathrm{T}}$ & santigrat \\
\hline
\end{tabular}

\section{SICAK ÇATLAK OLUŞUMU}

Alaşımlar; metallerin kabiliyetlerinin artırılmasına yönelik olarak homojen bir şekilde bir araya getirilmesidir. Düşük/alçak alaşımlı çelikler, endüstriyel alanda yaygın kullanıma sahip alaşımlardır. $\mathrm{Bu}$ alaşımlarda, toplam alaşım oranının \%8'ün altındadır [6]. Düşük/alçak alaşımlı çeliklerin kaynaklarda kullanımı hususunda en temel problem sıcak çatlakların oluşmasıdır [7]. Sicak çatlakların oluşumunda; metallerin oransal dağılımı ve kaynakla ilgili ortam parametrelerinin etkili olduğuna dair çalışmalar mevcuttur. 
Alaşımların kaynak kabiliyeti üzerine etkisi araştırmak üzere yürütülen bilimsel çalışmaları iki temel kategoride toplamak mümkündür. Yaygın olarak kullanılan ilk kategori; fiziksel modellerdir. Fiziksel modellerde daha çok malzemenin mekanik ve 1sıl davranışı üzerinde durulmakta ve mikro düzeydeki değişiklikler gözlenmektedir. Matematiksel modellerde ise amaç mevcut deney sonuçlarını açıklayabilecek en iyi matematiksel eşitliğin oluşturulmasıdır. Matematiksel modellerde anlamlandırma işlemi; model ortaya çıktıktan sonra yapılmaktadır.

Fiziksel modelleme çalışmaları; çeliklerin kaynak kabiliyetine etkisi bakımından alaşım elementleri hususunda şu temel kaidenin geçerli olduğunu ortaya koymaktadır: alaşım elementi azaldıkça kaynak kabiliyeti artmaktadır [8]. Skandiyum (Sc) ve Titanyum (Ti) gibi elementlerin ise sicak çatlamayı önleyebildiği düşünülmektedir [9]. Bilimsel yazımda, sıcak çatlama dayanımın test edilmesine yönelik farklı birçok yöntem önerilmiştir. Bu yöntemlerden bazıları: Varestraint testi, Fissure Bend testi, Dairesel Yama (Circular Patch) testi, Houldcroft testi, Sıcak Süreklilik testi (Hot ductility) ve Gerginlik Yüklemeli Çatlak Açma (Strain-Induced Crack Opening) testidir [10]-[13].

Sıcak kaynakların oluşumu üzerindeki etkenleri araştıran matematiksel model içerikli çalışmalar ise olduksa sınırlı sayıdadır. $\mathrm{Bu}$ çalışmada kullanılan verilerin aynısı kullanarak gerçekleştirilen bir yapay sinir ağ çalışması [5] bulunmaktadır. Bahsi geçen çalışmada değişik model önerileri arasından en yüksek doğruluk yüzdesine sahip yapay sinir ağ yapıları okuyuculara sunulmuştur. Verilerin \%50'sinin öğrenme/eğitim amacıyla kullanıldığı çalışmada model doğruluğu en yüksek \%75'lerde kalmıştır. En yüksek doğruluğa sahip model yapısı tüm veriler dâhil edilerek tekrar eğitildiğinde doğruluk \%90’lara ulaşmıştır.

\section{METOT VE SONUÇLAR}

Bu çalışmada, Cambridge Üniversitesi'nin Malzeme Algoritmaları Projesi kapsamında gerçekleştirilen deney sonuçlarının yayınladığı; "Malzeme Veri Kütüphanesi"ndeki veri setleri [5] kullanılarak; sıcak çatlamayı belirleyen faktörlerin matematiksel olarak modellenmesi amaçlanmıştır. $\mathrm{Bu}$ amaçla kurulan matematiksel modellerde bağımlı değişken olarak tanımlanan "çatlama varlığı"; var (1) ya da yok (0) değerlerini sınıflama değişkeni olarak ele almaktadır. Bu nedenle incelenen problem matematiksel olarak tipik bir sinıflandırma problemidir.

Sinıflandirma problemlerinde, girdileri sinıf etiketine eşleyen fonksiyonun ve parametrelerinin tahmin edilmesi amaçlanır. Eğitilmiş bir sınıflandırıcı kullanılarak hesaplanan sınıflandırma hatasının minimum değere sahip olması analizin esasını oluşturmaktadır [14].

Bu çalışmada; Waikato Üniversitesi tarafindan geliştirilen Java programlama dili tabanlı Weka (Waikato Environment for Knowledge Analysis) programı sınıflandırma amaçlı kullanılmıştır. Modelin doğruluk değerinin yükseltilmesi amacıyla pek çok sınıflandırma, regresyon, demetleme ve bağıntı kuralları algoritmaları denenmiştir. Tüm bu algoritmaların parametreleri, yaygın olarak kullanılan ve varsayılan değerler olarak bilinen değerlerde bırakılmıştır, böylelikle model başarımına belirgin bir etki oluşturulmasından kaçınılmıştır.

Algoritmaları çalıştırırken test yöntemi olarak "Rassal Öğrenme Verisi Seçimi” metodu kullanılmıştır. $\mathrm{Bu}$ yöntemle verilerin \%50si öğrenme/eğitim modeli geliştirilmesi için ayrılmış ve geri kalan kısmı ise geliştirilen modelin test edilmesi amacıyla kullanılmıştır. Deneme yapılan modellerden doğruluk değeri \%70'in üzerinde olan algoritmalar Çizelge 2'de sunulmuştur. Her bir 
algoritma denemesi için ilgili algoritma $100 \mathrm{kez}$ koşturulmuş ve başarım oranları bu koşturumların ortalaması alınarak hesaplanmıştır. \%81,8 doğrulukla "En İyi İlk Karar Ağacı" (BFTree) en iyi çözüm üreten yöntem olmuştur. Tüm ölçütler bakımından (doğruluk, kesinlik, duyarlılık ve Fölçütü) "En İyi İlk Karar Ağacı”nın en üst sırada yer alması; sinıflandırma yöntemi olarak kullanılabilirliğini işaret etmektedir.

Çizelge 2. Model başarım değerleri

\begin{tabular}{|l|c|c|c|c|}
\hline Algoritma & Doğruluk & Kesinlik & Duyarlılık & F Ölçütü \\
\hline $\begin{array}{l}\text { Lojistik } \\
\text { Regresyon } \\
\text { Algoritmas1 }\end{array}$ & $\% 79,2$ & $\% 80,4$ & $\% 79,2$ & $\% 78,2$ \\
\hline Naive Bayes & $\% 75,3$ & $\% 78,3$ & $\% 75,3$ & $\% 73,1$ \\
\hline K Star & $\% 74,0$ & $\% 73,7$ & $\% 74,0$ & $\% 73,7$ \\
\hline BFTree & $\% 81,8$ & $\% 81,8$ & $\% 81,8$ & $\% 81,6$ \\
\hline $\begin{array}{l}\text { J48 } \\
\text { Algoritmas1 }\end{array}$ & $\% 70,1$ & $\% 69,8$ & $\% 70,1$ & $\% 69,8$ \\
\hline
\end{tabular}

"En İyi İlk Karar Ağacı" algoritmik olarak en iyi sonucu veren ağaç dalından ilerlenmesi esası üzerine inşa edilmiş bir karar ağacı algoritmasıdır [15]. Her yeni dal oluşturma aşamasında; tüm uygun olasılıklar üzerinde en iyi küme seçilir ve işlem tüm düğümler saf (pure) hale gelinceye kadar devam ettirilir.

$\mathrm{Bu}$ çalışmada elde edilen karar ağacının tamamı Çizelge 3 'te, temel belirleyicileri içeren şematik gösterim ise Şekil 1'de sunulmuştur. Çizelge 3'de sonuç sütunun boş olduğu satıllar; kuralın alt döngülerle devam ettiğini göstermektedir. Sonuçların listelendiği sütunda, parantez içindeki sayılardan ilki kuralın doğru çalıştı̆ı deney sayısını; ikincisi ise yanlış çalıştığı deney sayısını göstermektedir. Geliştirilen kurallar; toplam 154 deney sonucuyla kıyaslanmış ve 125 'inin doğru çalıştığı görülmüsştür.
Çizelge 3. Elde edilene karar ağacı kuralları

\begin{tabular}{|c|c|}
\hline Kural (Ĕger....ise) & $\begin{array}{c}\text { Sonuç } \\
\text { (Çatlama } \\
\text { Var/Yok) }\end{array}$ \\
\hline Sülfür Yüzdesi < 0,0185 & \\
\hline |Nikel Yüzdesi < 3,2145 & \\
\hline | |Karbon Yüzdesi < 0,1045 & \\
\hline | | |Nikel Yüzdesi < 2,526 & \\
\hline|||| Karbon Yüzdesi $<0,047$ & \\
\hline|||| $\mid$ Karbon Yüzdesi $<0,0225$ & Yok $(4 / 0)$ \\
\hline|||| $\mid$ Karbon Yüzdesi $>=0,0225$ & \\
\hline|||||| Karbon Yüzdesi $<0,043$ & \\
\hline|||||| $\mid$ Karbon Yüzdesi $<0,034$ & Yok $(1 / 1)$ \\
\hline|||||| $\mid$ Karbon Yüzdesi $>=0,034$ & $\operatorname{Var}(4 / 0)$ \\
\hline|||||| Karbon Yüzdesi $>=0,043$ & Yok $(2 / 2)$ \\
\hline ||||Karbon Yüzdesi >=0,047 & \\
\hline|||| $\mid$ Karbon Yüzdesi $<0,094$ & \\
\hline|||||| Karbon Yüzdesi $<0,0535$ & \\
\hline|||||| $\mid$ Karbon Yüzdesi <0,0525 & Yok $(3 / 0)$ \\
\hline|||||| $\mid$ Karbon Yüzdesi $>=0,0525$ & $\operatorname{Yok}(1 / 1)$ \\
\hline|||||| Karbon Yüzdesi >=0,0535 & Yok $(63 / 0)$ \\
\hline|||| $\mid$ Karbon Yüzdesi $>=0,094$ & Yok $(3 / 2)$ \\
\hline || |Nikel Yüzdesi $>=2,526$ & \\
\hline|| $\mid$ Sülfür Yüzdesi $<0,0115$ & Yok (11/2) \\
\hline |||| |Sülfür Yüzdesi >= 0,0115 & \\
\hline ||||| |Nikel Yüzdesi <2,8575 & \\
\hline|||||| Sülfür Yüzdesi < 0,0125 & $\operatorname{Var}(2 / 0)$ \\
\hline|||||| Sülfür Yüzdesi >= 0,0125 & \\
\hline|||||| $\mid$ |Nikel Yüzdesi <2,7495 & Yok $(5 / 1)$ \\
\hline|||||| $\mid$ Nikel Yüzdesi >=2,7495 & $\operatorname{Var}(2 / 1)$ \\
\hline | | | | |Nikel Yüzdesi >= 2,8575 & $\operatorname{Var}(6 / 0)$ \\
\hline | |Karbon Yüzdesi >=0,1045 & $\operatorname{Var}(4 / 0)$ \\
\hline $\mid$ Nikel Yüzdesi >= 3,2145 & $\operatorname{Var}(13 / 0)$ \\
\hline Sülfür Yüzdesi >= 0,0185 & \\
\hline |Silikon Yüzdesi < 0,1875 & $\operatorname{Var}(2 / 1)$ \\
\hline $\mid$ Silikon Yüzdesi >= 0,1875 & $\operatorname{Var}(17 / 0)$ \\
\hline
\end{tabular}




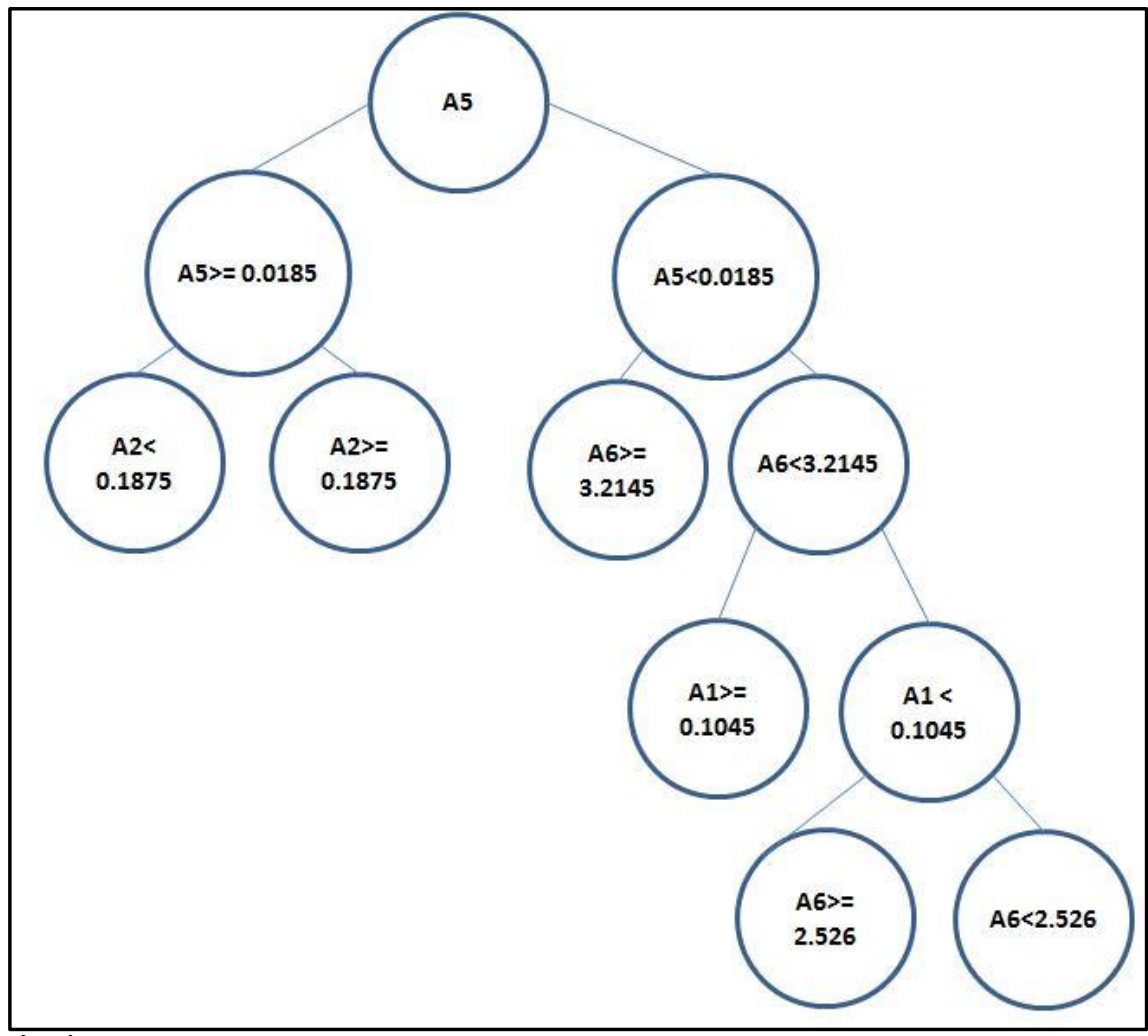

Şekil 1. "En İyi İlk Karar Ağacı” yöntemiyle elde edilen karar ağacı görünümü

\section{SONUÇLARIN YORUMLANMASI}

Şekil 1'de gösterildiği üzere karar ağacında sıcak çatlak oluşumunu belirleyen ana faktör "Sülfür yüzdesi” (A5) olmuştur. Sülfür miktarındaki yükseklik $(>\% 1,85)$, Şekil 2'de gösterildiği üzere sıcak çatlakların oluşumunu tetiklemektedir. Ancak; yüksek sülfür varlığı durumunda, "Silikon yüzdesi”ndeki (A2) artış dengeleyici bir unsur olarak çatlamaları azaltmaktadır. Sülfür miktarındaki her türlü azalmanın, katılaşma çatlamalarına karşı direnci artırabileceği gerçeğine karşın tamamen yok edemeyeceği de açıktır.

$\mathrm{Bu}$ durumda (sülfür yüzdesi <\%1,85), karar ağacında görüldüğü üzere ilk belirleyici faktör "Nikel yüzdesi" (A6) olmaktadır. Nikel yüzdesi \%3,2'den büyük olan tüm alaşımlı kaynaklarda (13 durum) sicak çatlama gözlenmiştir.
Deney parametresi olarak kullanılan çevresel faktörlerin (A9-Kaynak akım şiddeti, A10-Kaynak çalışma gerilimi, A11-Kaynak hareket hızı, A12-Kaynak açısı, A13-Ön 1sıtma derecesi) karar ağaçlarında bir dal oluşturmadıkları ve sonuç üzerinde etki doğurmadıkları anlaşılmıştır. Ayrıca alaşım malzemesi olarak veri setinde yer alan ve analize tabii tutulmalarına rağmen; karar ağacında etkileyici değere sahip olmayan metaller de söz konusudur. Bu metaller; Manganez, Fosfor, Krom ve Molibdendir.

Çalışma sonuçlarını kıyaslanması için, Ichikawa ve arkadaşlarının, 1996 yılında gerçekleştirdikleri çalışma [5] dikkate alınmıştır. Yazarlar, yapay sinir ağlarını kullanılarak oluşturdukları modellerde; model doğruluğu en yüksek 75\%'lere ulaşabilmiştir. $\mathrm{Bu}$ çalışmada ise; aynı veri seti, aynı parametreler (öğrenme seti/test seti oranı-1:1) kullanılarak; $\% 81,8 \quad$ doğruluk seviyesi yakalanabilmiştir. 


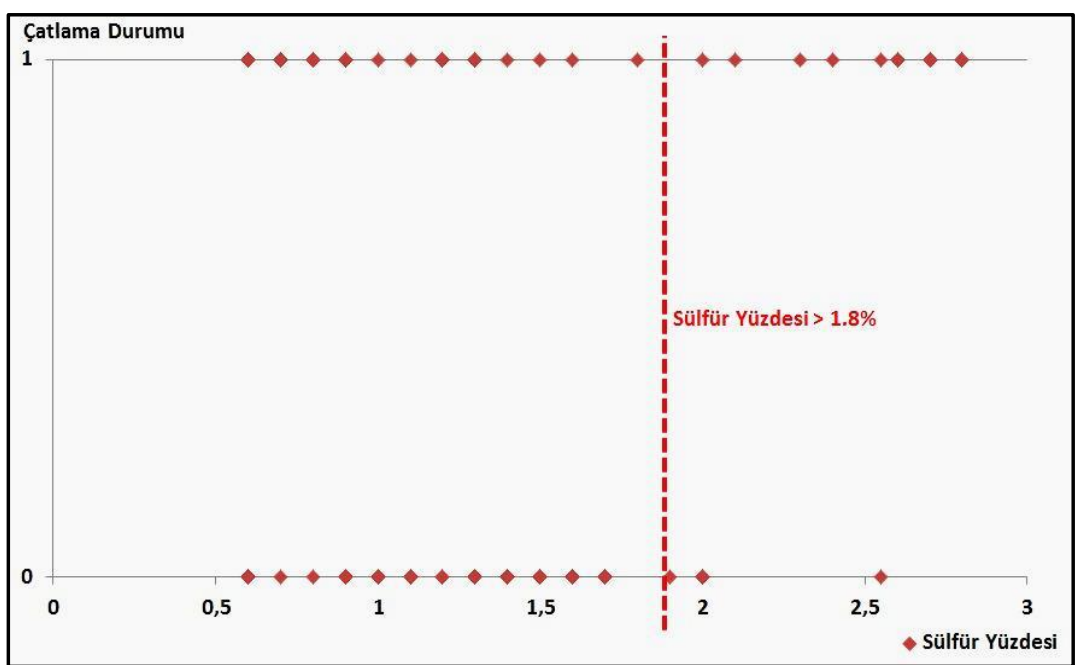

Şekil 2. Sülfür yüzdesi ve sıcak çatlama durumu (0: Çatlama Yok; 1: Çatlama Var)

Ichikawa ve arkadaşları, geliştirdikleri modeli tüm verileri dahil ederek tekrar eğitmiş doğruluk oranının \%90'lara yaklaştığını gözlemlemiştir. Bu çalışmada da aynı uygulama gerçekleştirilmiş (model tüm verileri dâhil ederek tekrar eğitilmiş) ve doğruluk oranı \%92,9'a yükselmiştir.

\section{KAYNAKLAR}

1. Cheng, C. M., Chou, C. P., Lee, I. K., Lin, H. Y., 2005. Hot Cracking of Welds on Heat Treatable Aluminium Alloys, Science and Technology of Welding and Joining, 10(3), 344-352.

2. Anık, S., Vural, M., 2007. Kaynak Dikişlerindeki Sıcak Çatlakların Nedenleri ve Önlenmesi, Mühendis ve Makine, 48(573), 5254.

3. Bordreuil, C., Niel, A., 2014. Modelling of Hot Cracking in Welding with a Cellular Automaton Combined with an Intergranular Fluid Flow Model, Computational Materials Science, 82, 442-450.

4. DuPont, J. N., Robino C. V., Marder, A. R., 1999. Modelling Mushy Zones in Welds of Multicomponent Alloys: Implications for Solidification Cracking, Science and Technology of Welding and Joining, 4(1), 114.
5. Ichikawa, K., Bhadeshia, H. K. D. H., MacKay D. J. C., 1996. Model for Solidification Cracking in Low Alloy Steel Weld Metals, Science and Technology of Welding and Joining, 1(1), 43-50.

6. ASM Handbook Committee, 1991. Classification and Designation of Carbon and Low-Alloy Steels, in ASM Handbook, 10th ed., 1, ASM International, 140-194.

7. Kou, S., Solidification and Liquation Cracking Issues in Welding, JOM, 55(6), 37-42.

8. Oğuz, B., 1985. Karbonlu ve Alaşımlı Çeliklerin Kaynağı, Oerlikon Yayınları.

9. Mousavi, M. G., Cross, C. E., Grong, O., 1999. Effect of Scandium and Titanium-Boron on Grain Tefinement and Hot Cracking of Aluminium Alloy 7108, Science and Technology of Welding and Joining, 4(6), 381388 .

10. Savage, W. F., Lundin, D. D., 1965. The Varestraint Test, Welding Journal, (44)10, 433442.

11. Gittos, N. F., Scott, M. H., 1987. Heat-Affected Zone Cracking of Al-Mg-Si Alloys, Welding Journal, 60(6) 95-103.

12. Lundin, C. D., Lingenfelter, G. E., Grotke, G. E., Matthews, S. J., 1982. The Varestraint Test, WRC Bulletin, 280, New York, NY, USA: Welding Research Council. 
13. Lundin, C. D., Spond, D. F., 1976. The Nature and Morphology of Fissures in Austenitic Stainless Steel Weld Metals, Welding Journal, 55(11), 356-367.

14. Başer, F., Apaydın, A., 2015. Sınıflandırma Amaçlı Destek Vektör Makinelerinin Lojistik Regresyon ile Karşılaştırılması, Anadolu University of Sciences \& Technology-B: Theoretical Sciences, 3(2), 53-65.

15. Shi, H., 2007. Best-first Decision Tree Learning, Yüksek Lisans Tezi, University of Waikato. 
